\title{
The Grey-Based Taguchi Method: Optimisation of Drilling of Hybrid Aluminum Matrix Composites
}

\author{
M. Ay ${ }^{a, *}, \mathrm{Y}$. AltunPaK ${ }^{b}$ And S. HARTOMACIOĞLU ${ }^{a}$ \\ ${ }^{a}$ Marmara University, Faculty of Technology, Department of Mechanical Engineering, 34722, Istanbul, Turkey \\ ${ }^{b}$ Abant Izzet Baysal University, Faculty of Engineering and Architecture, \\ Mechanical Engineering, 14280, Bolu, Turkey
}

\begin{abstract}
The aim of this study was to investigate the influence of cutting parameters and effect of graphite rate on cutting force and surface roughness in drilling of $\mathrm{Al} / 20 \% \mathrm{SiC} / 5 \% \mathrm{Gr}, \mathrm{Al} / 20 \% \mathrm{SiC} / 7.5 \% \mathrm{Gr}$ and $\mathrm{Al} / 20 \% \mathrm{SiC} / 10 \% \mathrm{Gr}$ hybrid composites, fabricated by vortex method. The drilling tests are conducted with diamond-like-carbon coated cutting tools. The Grey relational analysis based Taguchi optimization method was selected to determine the optimum cutting conditions. The results show that the spindle speed $(4500 \mathrm{rpm})$, the rate of graphite $(10 \%)$ and feed $(0.1 \mathrm{~mm} / \mathrm{rev})$ were found to be significant parameters for surface roughness and cutting force. The predicted values from the developed model and experimental values are found to be very similar in this study.
\end{abstract}

DOI: 10.12693/APhysPolA.131.551

PACS/topics: 81.05.- -t

\section{Introduction}

Due to their high strength, fracture toughness, wear resistance and stiffness, aluminum alloys are preferred in aerospace and automobile sectors. Unique combination of such properties makes aluminum matrix composites (AMCs) potential candidates for many applications, such as brake drums/rotors, cylinder liners, connecting rods, cylinder blocks, pistons, gears, drive shafts and suspension components. When ceramics such as $\mathrm{SiC}, \mathrm{Al}_{2} \mathrm{O}_{3}$, $\mathrm{TiC}, \mathrm{TiO}_{2}, \mathrm{SiO}_{2}, \mathrm{Si}_{3} \mathrm{~N}_{4}, \mathrm{~B}_{4} \mathrm{C}, \mathrm{BN}$ and $\mathrm{AlN}$, are added as reinforcement, they make the materials harder and an intense abrasive wear on tool was found, which increases the cutting forces. This results in poor tool life and inconsistent part quality and thus limits the use of metal matrix composites (MMCs) in many applications [1-7]. $\mathrm{Al} / \mathrm{SiC}-\mathrm{Gr}$ hybrid aluminum matrix composites are used for high performance "ceramic" brake discs as these are able to withstand extreme temperatures. Several studies have investigated the effect of graphite on the physical and mechanical properties of MMCs. Sharma et al. [9] reported that the tool life of HSS drill gets increased while machining the graphite-reinforced aluminum matrix composites, compared to the base alloy. There is a reduction in energy required for drilling the composite, compared to the base alloy, since graphite being a solid lubricant, reduces the friction at tool-work piece interface. Authors of [9] have reported that ceramicgraphite reinforced composite has a better machinability than those reinforced with silicon carbide particles only $[6-10]$.

In the view of the growing engineering applications of these composites, a need for detailed and systematic study of their machining characteristics is envisaged.

*corresponding author; e-mail: muay@marmara.edu.tr
The efficient and economical machining of these materials is required for obtaining the desired dimensions and surface finish [11-12]. Taguchi technique provides a simple, efficient and systematic approach to optimize the design for performance, quality and cost [12]. Engineering optimization of a process or a product should be carried out in a three-step approach, i.e. system design, parameter design, and tolerance design. Analysis of variance (ANOVA) is also employed to analyze the machining characteristics of these composites [12-16]. In recent years, the rapid growth of interest in the Taguchi method has led to numerous applications of the method in a worldwide range of industries and nations [16, 17]. The response surface methodology (RSM) based on Grey theory was used to minimize the surface roughness in nontraditional cutting processes. Since Taguchi method is intended to optimize only single response characteristic, the Grey relational analysis is used to optimize multiple outcomes. Optimization of the input processing parameters is done by using an effective Grey-based differential evolution algorithm. Grey relational analysis has been used for converting the multi-objective function into single objective, which will be the objective function in the differential evolution algorithm [18-20].

There is still a need for the detailed, economic and systematic study of the machining characteristics in engineering applications of these composites. The paper aims to identify the cutting parameters and the effect of graphite rate on surface roughness and cutting force in drilling of $\mathrm{Al} / 20 \% \mathrm{SiC} / 5 \% \mathrm{Gr}, \mathrm{Al} / 20 \% \mathrm{SiC} / 7.5 \% \mathrm{Gr}$ and $\mathrm{Al} / 20 \% \mathrm{SiC} / 10 \% \mathrm{Gr}$ hybrid composites. In order to determine the optimum cutting conditions, Taguchi method was used in the experimental design step. Grey relational analysis method was used in the optimization step.

\section{Materials and methods}

$$
\text { 2.1. Materials }
$$

All composites were fabricated under similar process conditions. Aluminum (LM2) is used as the main matrix 
material. The Al-Si-Cu matrix alloy has in its composition (\% by weight) $\mathrm{Si}(12 \max ), \mathrm{Cu}$ (0.7 to 0.9), Fe (0.7 max), Mn (0.25 max), Mg (0.02 $\max ), \mathrm{Zn}(0.3$ $\max ), \mathrm{Ni}(0.03 \max ), \mathrm{Ti}(0.03 \max ), \mathrm{Pb}(0.09 \max )$, $\mathrm{Al}$ (balance). Average particle size of $\mathrm{SiC}$ and graphite was $53 \mu \mathrm{m}$ and $90 \mu \mathrm{m}$, respectively. $\mathrm{Al} / 20 \% \mathrm{SiC} / 5 \% \mathrm{Gr}$, $\mathrm{Al} / 20 \% \mathrm{SiC} / 7.5 \% \mathrm{Gr}$ and $\mathrm{Al} / 20 \% \mathrm{SiC} / 10 \% \mathrm{Gr}$ hybrid composites were fabricated by vortex method and then formed by squeeze casting method, described in our previous study [1].

All drilling tests were performed on JohnFord vertical CNC machining center. The machining samples were prepared in the form of $100 \times 10 \times 10 \mathrm{~mm}^{3}$ blocks for each material. The diamond like carbon (DLC Drill regular NACHI DLCDR5.0 LIST 9520) coated cutting tools of $5 \mathrm{~mm}$ diameter were used. A fresh tool was used to drill each material (three holes) for all cutting conditions. The point angles were $118^{\circ}$.

\subsection{Experimental procedure}

The experiments were performed at different speeds of 3500,4000 and $4500 \mathrm{rpm}$ and at feed rates of 350, 400 and $450 \mathrm{~mm} / \mathrm{min}(0.1,0.13$ and $0.16 \mathrm{~mm} / \mathrm{rev})$ as given in Table I. The experimental conditions were presented in detail in an earlier publication [1]. Coolant was not used in any of the drilling tests. In the experiment design, there were three parameters at three levels. If the full factorial experimental design used, $\left(3^{3}\right) 27$ experiments must be conducted. To reduce the number of experiments, the Taguchi L9 orthogonal array was used.

TABLE I

Experiment factors and their levels.

\begin{tabular}{c|c|c|c}
\hline \hline Parameters & $\begin{array}{c}\text { (A) Spindle } \\
\text { speed [rpm] }\end{array}$ & $\begin{array}{c}\text { (B) Feed } \\
{[\mathrm{mm} / \mathrm{rev}]}\end{array}$ & $\begin{array}{c}\text { (C) Rate of } \\
\text { graphite [\%] }\end{array}$ \\
\hline Level I & 3500 & 0.1 & 5 \\
Level II & 4000 & 0.13 & 7.5 \\
Level III & 4500 & 0.16 & 10.0
\end{tabular}

\subsection{Taguchi-based Grey relational analysis method}

The obtained experimental results and the determined parameters were optimized with Grey-based Taguchi method. Using regression model, calculation of an equation between dependent parameters and independent parameters was carried out. The Taguchi method uses a special design of orthogonal arrays to study the entire parameter space with a small number of experiments only.

Experimental design was done using Taguchi method. Hence, it has been possible to reach more comprehensive results with doing less experiment. In this sense, time and money have been used more efficiently $[15,16]$. While a single outcome is optimized in the Taguchi method, multiple outcomes can be optimized in Grey relational analysis [19]. In this study, Taguchi method was used in the experimental design step, Grey relational analysis method was used in the optimization step.

Grey relational analysis optimization process was carried out in the following three steps [19]:
1. Normalization of experimental results (the lowest is the best);

2. Calculation of the Grey relational coefficient;

3. Calculation of the Grey relational degree.

In the normalization step, the experimental results were normalized using the following equation, according to "the lowest is the best" principle.

$$
x_{i}(k)=\frac{\max y_{i}(k)-y_{i}(k)}{\max y_{i}(k)-\min y_{i}(k)} .
$$

Here, $x_{i}(k)$ refers to the value of the $i$ th series and $k$ row after normalization process, $\min y_{i}(k)$ refers to the minimum value of the $i$ th series, $\max y_{i}(k)$ refers to the maximum value of the $i$ th series and $y_{i}(k)$ refers to the original value of the $i$ th series and $k$ row.

The step 2, Grey relational coefficient, was calculated via Eq. (2)

$$
\xi_{i}(k)=\frac{\Delta \min +\zeta \Delta \max }{\Delta 0_{i}(k)+\zeta \Delta \max } .
$$

Here, $\zeta$ is a distinguishing coefficient between 0 and 1 , $\Delta 0_{i}$ is the amount of deviation between the reference series and the normalization values. $\Delta$ min refers to the minimum value of the deviation sequence from the reference series and $\Delta$ max refers to the maximum value of deviation sequence from the reference series.

The step 3, Grey relational degree, was calculated using Eq. (3)

$$
\gamma_{i}=\frac{1}{n} \sum_{k=1}^{n} \xi_{i}(k) \text {. }
$$

\section{Results and discussion}

Influence of the cutting parameters and the effect of graphite on surface roughness $R a$ and cutting force $N$ during drilling of a hybrid $\mathrm{Al} / \mathrm{SiC} / \mathrm{Gr}$ MMCs with DLC coated drills is discussed in this section.

\section{TABLE II}

Taguchi $\mathrm{L}_{9}$ experiment design, surface roughness and cutting force.

\begin{tabular}{c|c|c|c}
\hline $\begin{array}{c}\text { Exper. } \\
\text { No. }\end{array}$ & Variables & $\begin{array}{c}\text { Surf. roughness, } \\
R a[\mu \mathrm{m}]\end{array}$ & $\begin{array}{c}\text { Cutting } \\
\text { force }[\mathrm{N}]\end{array}$ \\
\hline 1 & $\mathrm{~A}_{1} \mathrm{~B}_{1} \mathrm{C}_{1}$ & 0.511 & 703.31 \\
2 & $\mathrm{~A}_{1} \mathrm{~B}_{2} \mathrm{C}_{2}$ & 0.746 & 572.64 \\
3 & $\mathrm{~A}_{1} \mathrm{~B}_{3} \mathrm{C}_{3}$ & 1.014 & 509.95 \\
4 & $\mathrm{~A}_{2} \mathrm{~B}_{1} \mathrm{C}_{2}$ & 0.507 & 369.71 \\
5 & $\mathrm{~A}_{2} \mathrm{~B}_{2} \mathrm{C}_{3}$ & 0.741 & 348.82 \\
6 & $\mathrm{~A}_{2} \mathrm{~B}_{3} \mathrm{C}_{1}$ & 0.597 & 878.62 \\
7 & $\mathrm{~A}_{3} \mathrm{~B}_{1} \mathrm{C}_{3}$ & 0.595 & 324 \\
8 & $\mathrm{~A}_{3} \mathrm{~B}_{2} \mathrm{C}_{1}$ & 0.429 & 698.91 \\
9 & $\mathrm{~A}_{3} \mathrm{~B}_{3} \mathrm{C}_{2}$ & 0.685 & 498.23
\end{tabular}

Taguchi L 9 experiment design, surface roughness, cutting force values obtained in experiment are shown in Table II. 
Grey relational analysis method was applied to the experimental results. The normalized data, delta values, Grey relational coefficients and Grey relational grade results are given in Table III. The Grey relational coefficients were calculated using Eq. 2.

TABLE III

The normalized data, delta values, Grey relational coefficients and Grey relational grade results.

\begin{tabular}{c|c|c|c|c|c|c|c|c}
\hline \hline \multirow{2}{*}{$\begin{array}{c}\text { Exp. } \\
\text { No }\end{array}$} & \multicolumn{2}{|c|}{$\begin{array}{c}\text { Normalized } \\
\text { data }\end{array}$} & \multicolumn{2}{c|}{$\begin{array}{c}\text { Delta } \\
\text { values }\end{array}$} & \multicolumn{2}{c|}{$\begin{array}{c}\text { Grey relational } \\
\text { coefficients }\end{array}$} & \multicolumn{2}{c}{$\begin{array}{c}\text { Grey relational } \\
\text { grade }\end{array}$} \\
\cline { 2 - 9 } & $\begin{array}{c}\text { Cutting } \\
\text { force }\end{array}$ & $\begin{array}{c}\text { Surface } \\
\text { roughness }\end{array}$ & $\begin{array}{c}\text { Cutting } \\
\text { force }\end{array}$ & $\begin{array}{c}\text { Surface } \\
\text { roughness }\end{array}$ & $\begin{array}{c}\text { Cutting } \\
\text { force }\end{array}$ & $\begin{array}{c}\text { Surface } \\
\text { roughness }\end{array}$ & $\begin{array}{c}\text { GRA } \\
\text { values }\end{array}$ & $\begin{array}{c}\text { GRA } \\
\text { rank }\end{array}$ \\
\hline 1 & 0.3161 & 0.8598 & 0.6839 & 0.1402 & 0.4223 & 0.7810 & 0.922 & 1 \\
2 & 0.5517 & 0.4581 & 0.4483 & 0.5419 & 0.5273 & 0.4799 & 0.860 & 2 \\
3 & 0.6647 & 0.0000 & 0.3353 & 1.0000 & 0.5986 & 0.3333 & 0.669 & 4 \\
4 & 0.9176 & 0.8667 & 0.0824 & 0.1333 & 0.8585 & 0.7895 & 0.635 & 3 \\
5 & 0.9552 & 0.4667 & 0.0448 & 0.5333 & 0.9178 & 0.4839 & 0.423 & 6 \\
6 & 0.0000 & 0.7128 & 1.0000 & 0.2872 & 0.3333 & 0.6352 & 0.457 & 7 \\
7 & 1.0000 & 0.7162 & 0.0000 & 0.2838 & 1.0000 & 0.6379 & 0.486 & 5 \\
8 & 0.3240 & 1.0000 & 0.6760 & 0.0000 & 0.4252 & 1.0000 & 0.372 & 8 \\
9 & 0.6859 & 0.5624 & 0.3141 & 0.4376 & 0.6141 & 0.5333 & 0.359 & 9
\end{tabular}

The Grey relational degrees related to each experiment result were calculated (Fig. 1) and the experiments results were ranked in order from highest Grey relational degree (Table III).

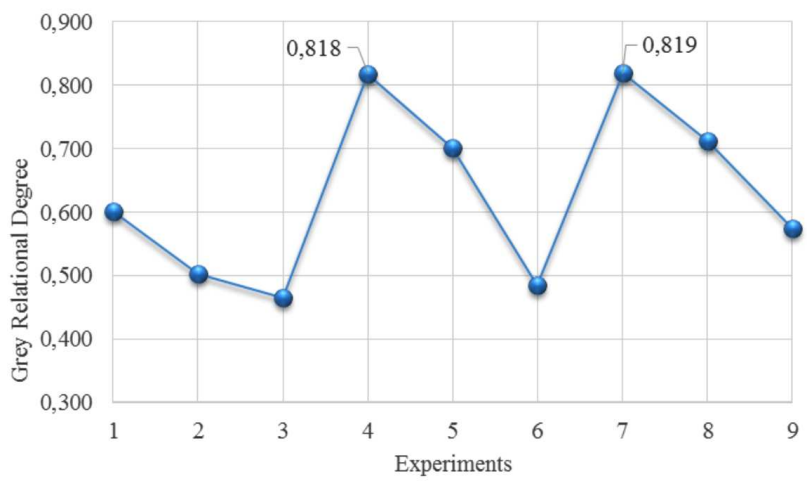

Fig. 1. Grey relational degrees for each experiment.

For the determination of optimal factor's levels, the Grey relational degree for each factor's level was calculated and results are shown in Table IV.

\section{TABLE IV}

Grey relational degrees of the factor levels.

\begin{tabular}{c|c|c|c}
\hline \hline Levels & $\begin{array}{c}\text { Spindle } \\
\text { speed (A) }\end{array}$ & Feed (B) & $\begin{array}{c}\text { Rate of } \\
\text { graphite }\end{array}$ \\
\hline Level 1 & 0.524 & 0.748 & 0.600 \\
Level 2 & 0.670 & 0.639 & 0.634 \\
Level 3 & 0.702 & 0.508 & 0.662
\end{tabular}

As seen from the Table IV, A3 (spindle speed of $4500 \mathrm{rpm}$ ), B1 (feed rate of $0.1 \mathrm{~mm} / \mathrm{rev}$ ), and C3 (rate of graphite of $10 \%$ ) were selected as the optimal parameter levels in the results. The optimal parameters levels will represent the lowest surface roughness and cutting force value.

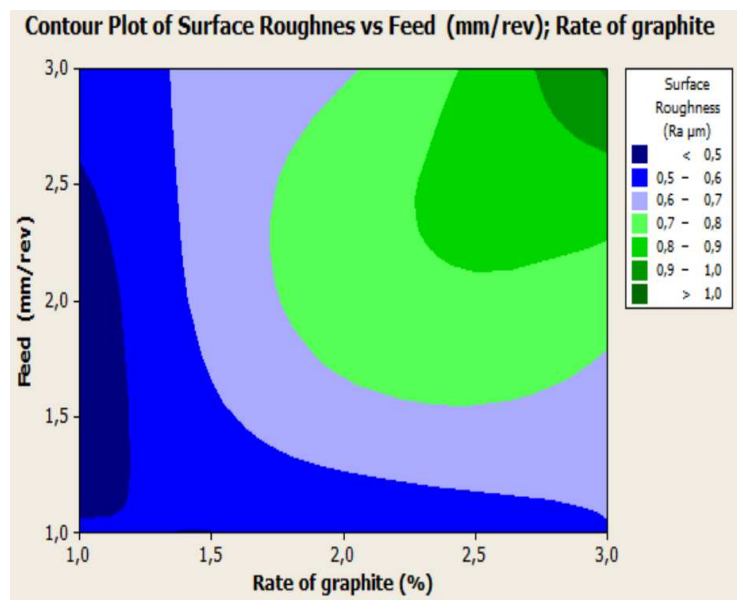

Fig. 2. Effects of rate of graphite and feed on surface roughness.

In drilling of the composites with cutting tools coated with DLC, nine experiments were carried out using three different factors at three different levels. Different $R a$ values were obtained from each experiment. The effect of rate of graphite and feed rate on surface roughness, during drilling of the produced composites, is shown in Fig. 2 and the effect of rate of graphite and feed rate on 
cutting force is shown in Fig. 3. The plots indicate that the increase of feed rate increases the surface roughness and cutting force, whereas the increase of graphite rate increases surface roughness but reduces the cutting force at all conditions. Similar results were obtained in our previous experimental study $[1,12]$, that the inclusion of graphite in the composites reduces the cutting force but increases the surface roughness.

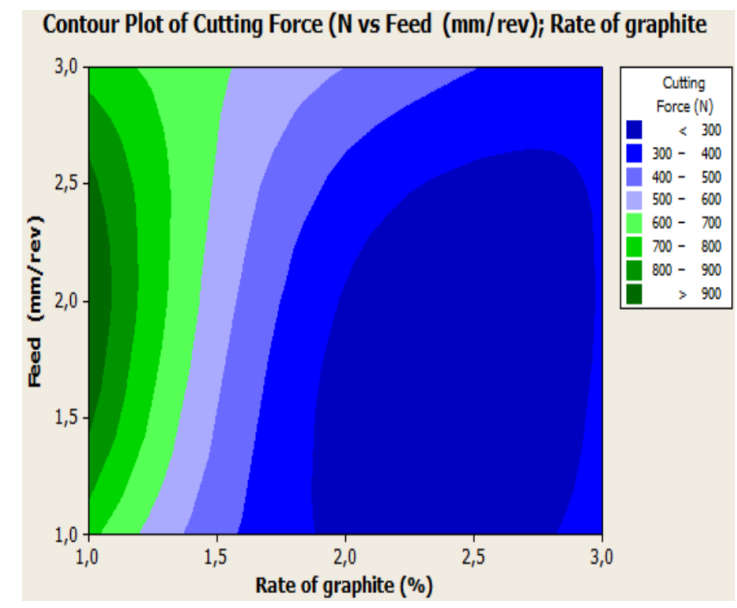

Fig. 3. Effects of rate of graphite and feed on cutting force.

\section{Conclusions}

This work discusses the drilling of $\mathrm{Al} / 20 \% \mathrm{SiC} / 5 \% \mathrm{Gr}$, $\mathrm{Al} / 20 \% \mathrm{SiC} / 7.5 \% \mathrm{Gr}$ and $\mathrm{Al} / 20 \% \mathrm{SiC} / 10 \% \mathrm{Gr}$ DLCcoated cutting tools at different cutting parameters. Taguchi's L $\mathrm{L}_{9}$ orthogonal array and Grey relational degree were used for finding the optimal process parameters for cutting force and surface roughness. The following conclusions can be drawn from the analysis of results.

1. Based on the analysis of Grey relational degree, the optimal cutting parameters were A3B1C3 for surface roughness and cutting force, i.e. spindle speed of $4500 \mathrm{rpm}$, feed of $0.1 \mathrm{~mm} / \mathrm{min}$ and graphite rate of $10 \%$, for both, the surface roughness and cutting force.

2. The plots indicate that the increase of feed rate increases the surface roughness and cutting force, whereas the increase of graphite rate increases surface roughness but reduces the cutting force at all conditions.

3. The predicted values from the developed model and experimental values are found to be very similar to each other, justifying thus the significance of the model.

\section{References}

[1] Y. Altunpak, M. Ay, S. Aslan, Int. J. Adv. Manuf. Technol. 60, 513 (2012).

[2] S.V. Prasad, R. Asthana, Tribol. Lett. 17, 445 (2004).

[3] M.T. Hayajneh, A.M. Hassan, A.T. Mayyas, J. Alloy Comp. 478, 559 (2009).

[4] S. Basavarajappa, G. Chandramohan, A. Mahadevan, M. Thangavelu, R. Subramanian, P. Gopalakrishnan, Wear 262, 1007 (2007).

[5] D. Gultekin, M. Uysal, S. Aslan, M. Alaf, M.O. Guler, H. Akbulut, Wear 270, 73 (2010).

[6] N. Kumar, G. Gautam, R.K. Gautam, A. Mohan, S. Mohan, J. Inst. Eng. India Ser. D 97, 233 (2016).

[7] A. Premnath, Particul. Sci. Technol. 34, 707 (2016).

[8] S.C. Sharma, B.M. Girish, R.S. Kulkarni, R. Kamath, NML Tech J. 38, 127 (1996).

[9] S. Basavarajappa, G. Chandramohan, J.P. Davim, Int. J. Mach. Tool. Manufact. 47, 92 (2007).

[10] A.M. Raj, S.L. Das, K. Palanikumarr, Indian J. Sci. Technol. 6, 5002 (2013).

[11] M. El-Gallab, M. Sklad, J. Mater. Proc. Technol. 83, 277 (1998).

[12] T. Rajmohan, K. Palanikumar, M. Kathirvel, Trans. Nonferrous Met. Soc. China 22, 1286 (2012).

[13] A.M. Ali, E.Y.T. Adesta, D. Augusman, S.N.M. Badari, M.H.F. Al-Hazza, Asian J. Scient. Res. 4, 255 (2011).

[14] M. Ay, Y. Altunpak, J. Eng. Fundament. 2, 42 (2015).

[15] G. Tosun, Int. J. Adv. Manuf. Technol. 55, 477 (2011).

[16] W.H. Yang, Y.S. Tarng, Int. J. Mater. Process Technol. 84, 122 (1998).

[17] T. Chung-Chen, H. Honk, Int. J. Mater. Processing Technol. 123, 1 (2002).

[18] K. Venkatesan, R. Ramanujam, V. Saxena, N. Chawdhury, V. Choudhary, ARPN J. Eng. Appl. Sci. 9, 250 (2014).

[19] M. Kurt, S. Hartomacioğlu, B. Mutlu, U. Köklü, $M a-$ ter. Technol. 46, 205 (2012).

[20] H. Ravikumar, P.L. Arun, S. Thileepan, Int. J. ChemTech. Res. 8, 292 (2015). 